\title{
Film Review: A Moment in the Reeds
}

\section{Sini-Petriina Klasto}

The quiet intensity of A Moment in the Reeds (2017) is instantly recognisable; London-based Mikko Mäkelä has evidently incorporated Finnishness as a part of his first feature. While superficially similar to God's Own Country (Francis Lee, 2017) and narratively comparable to Weekend (Andrew Haigh, 2011), A Moment in the Reeds holds its own by being a forthright romance - with a pinch of coldly served reality. Having claimed international recognition at numerous LGBTQ+ Film Festivals, the film was additionally nominated for two Jussis in 2018; Best Actor (Janne Puustinen) and Best Supporting Actor (Boodi Kabbani). The film's rather commonplace storyline of a gay/queer protagonist returning home to a difficult family reunion, with a father character that wobbles between a caricature and an accurate depiction of a racist homophobe, threaten to make A Moment in the Reeds a banal experience. However, it is the work and skill of the captivating actors, along with other intelligent and thoughtful artistic choices, that makes the film a respectable addition to the world of queer cinema.

To a queer audience the storyline of the film is hardly revelational, but it does offer some general insights into Finnish queer existence. Leevi, a Finnish literature student living in Paris, reluctantly returns home for the summer holidays and is forced to reckon with his estranged father, Jouko. With next to no common ground to speak of, the homophobic father and his gay son start renovating their summer cottage to prepare it for re-sale. Adhering to a common stereotype, Leevi is of little help with the renovation, and knowing this about his son, Jouko hires an extra pair of hands to help them. Unfortunately for Jouko, the hired labourer turns out to be Tareq, a Syrian refugee and an architect by training, an enthusiastic handsome man who does not speak Finnish.

Tareq's presence brings forth new dynamics in Leevi's and Jouko's relationship as Leevi is forced to adopt the role of an interpreter between his father and Tareq. While Jouko gets gradually more tense and uncomfortable, Leevi relaxes and savours his father's discomfort. When Jouko then suddenly has to leave to sort out a business emergency, the boys are left alone to enjoy a warm summer evening; which is when the initially implied sexual tension between the two develops into passion which is expressed through explicit erotic scenes.

The film is not unique in its thematic explorations. Homophobia and racism are common topics in queer cinema; reflecting the intersecting ways that they taint queer lived experiences. Yet somehow Mäkelä has brought a completely new sense of nuance and creative tension, establishing a calming cinematic atmosphere while exploring these heavy themes. It is also worth noting that A Moment in the Reeds is the first film that touches both racism and queer themes in the Finnish context. For that reason alone, this film feels like an honest breath of actuality. 
While some critics have disliked the film and considered it unoriginal and scarce, I disagree with these reviewers. Ilkka Salminen's cinematography may appear be basic at first but it grows more complex and fluid as the story develops; an artistic choice that is further complemented by a lack
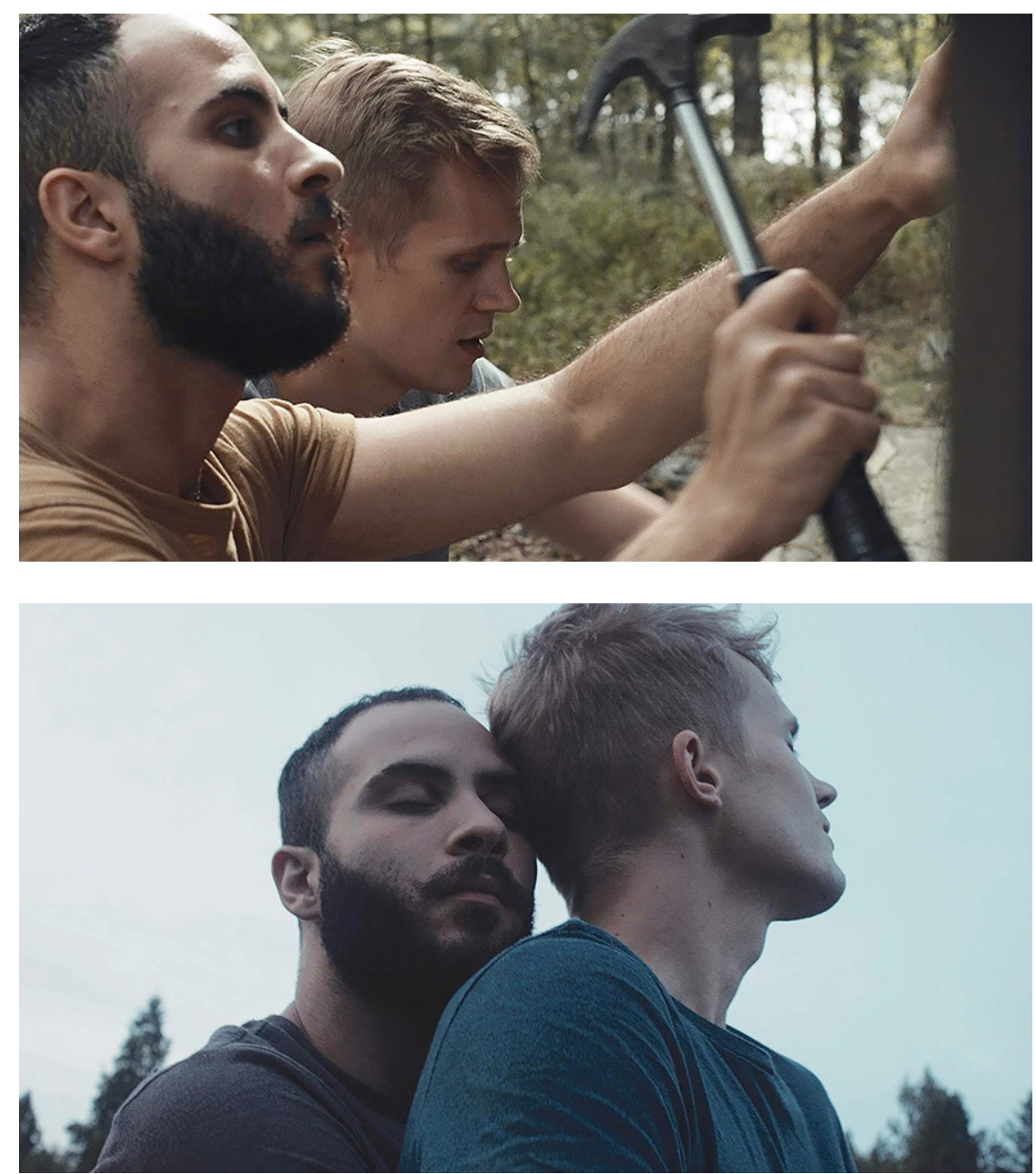

IMAGES: Tareq (Boodi Kabbani) and Leevi (Janne Puustinen) in Mikko Mäkelä's film A Moment in the Reeds (2017). @ Wild Beast Productions. of music in the first half of the film. The dialogue does not feel lacking, but plays with the phases of speech, making it more natural. Some of the dialogue is improvised by the actors, which potentially contributes to the overall natural flow of the script. Moreover, Finland does not have nearly enough Finnish queer representation on the big screen. Mäkelä has not only changed that but additionally managed to create a solid, believable narrative with very scarce resources. In short, while budgetary limitations have seemingly dictated some of the artistic choices, in the hands of a talented team these have been turned into strengths rather than weaknesses.

What is especially noteworthy about the film, is how well it mediates and explores the Finnish queer experience through the theme of queer escapism. Throughout the movie it is clear that Leevi is disgruntled for having had to return to Finland after experiencing a more satisfying life in France. Even after meeting Tareq, Leevi does not seem to quite believe that anything so special or wonderful could ever happen in his mother country. This depiction of queer escapism symbolised through Leevi, whereby Finland has come to represent negative multiplicity, is not uncommon among Finnish queers whom have chosen to exist outside of the borders of Finland. A Moment in the Reeds manages to carefully approach queer escapism as a theme without assigning blame to anyone, leaving judgments to the viewer's discretion.

A Moment in the Reeds is first and foremost a Finnish queer film, in production and context as well as in its artistic vantagepoint and filmic atmosphere. It is not overly ambitious or thematically pioneering, but takes its well-earned place in the world of queer cinema unapologetically, with recognisable Finnish humility, acknowledging its strengths without ostentation. It is worth seeing not only for the superb, convincing acting, or the amiable overall experience, but also for the simple joy of witnessing Finnish queer experience reflected upon and celebrated through film.

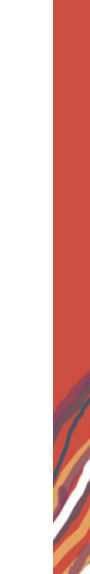

\section{.}

